\title{
Nigella sativa L. Seeds Biomass as a Potential Sorbent in Sorption of Lead from Aqueous Solutions and Wastewaters
}

\author{
ABDELHAMID ADDALA ${ }^{1}$, NOUREDDINE BELATTAR ${ }^{1 *}$ and MARIA ELEKTOROWICZ ${ }^{2}$ \\ ${ }^{1}$ Applied Biochemistry Laboratory, Department of Biochemistry, Ferhat Abbas University, \\ Setif 01, 19000 Setif, Algeria. \\ ${ }^{2}$ Department of Building, Civil and Environmental Engineering, Concordia University, Canada. \\ *Corresponding author E-mail: nbelattar@yahoo.com \\ http://dx.doi.org/10.13005/ojc/340205
}

(Received: November 10, 2017; Accepted: January 18, 2018)

\begin{abstract}
This first study aims to establish the adsorption capacity of Nigella sativa seeds, an agro-food waste towards $\mathrm{Pb}$ (II) according to batch mode by varying contact time, initial $\mathrm{Pb}$ (II) concentration, initial $\mathrm{pH}$ and sorbent dose. The amount of $\mathrm{Pb}$ (II) ion adsorbed at interface is found high in order of $90.31 \mathrm{mg} / \mathrm{g}$ under optimum conditions. The FTIR characterization indicates the involvement of the hydroxyl and carbonyl groups of the given material in the adsorption of $\mathrm{Pb}(\mathrm{II})$. Isotherm curves and kinetic studies demonstrate that the Langmuir model and pseudo-second order kinetic describe well the sorption phenomenon and fit best to the sorption experimental data. Removing trial of lead from activated sludge waste and its decanted effluent confirm the efficiency of this biomass, which attain $97 \%$ and $64 \%$ respectively. Based on the results, the Nigella sativa seeds waste biomass appears as a potential eco-friendly and low cost sorbent for sorption of lead from wastewaters.
\end{abstract}

Keyswords: Nigella seeds meals waste, Biosorption, Biomass sorbent, Heavy metal pollutants, Lead removal, Sorption isotherm

\section{INTRODUCTION}

In the field of environmental protection, removal of heavy metal pollutants from solid or liquid effluents constitutes a great challenge for health and environment institutions particularly in developing countries as a result of increasing industrial activities. Lead is one of the most used metals in batteries accumulators manufacturing and metal extraction and finishing activities. It can be considered as one of the most toxic heavy metals that have latent long-term negative impacts on health, causing anemia, encephalopathy, hepatitis and nephritic syndrome ${ }^{1}$. Therefore, there is urgent need for decontaminating these effluents before discharge them in the environment. Different 
technologies of treatment have been used and evaluated in removing toxic metals from industrial effluents based on various chemical or physical principles including precipitation by hydroxides, carbonates or sulfides ${ }^{2}$, adsorption on kaolinite and montmorillonite $^{3}$, membrane filtration ${ }^{4}$ and electrochemical methods such as electrocagulation and electrowinning ${ }^{5}$. In last decade, biosorption process which uses various materials of biological origin, including bacteria, fungi, yeast and algae as a bioadsorbents constitutes an alternative way in removing of metal pollutants ${ }^{6,7,8}$. Waste products from food industry and agricultural activities are another emerged technology and innovative eco-friendly solution to the problem of heavy metal pollution due their abundance, cost-effective and high efficiency in removing ions pollutants and without secondary effect on environment ${ }^{9}$. In fact, some achieved investigations on various cheap bioadsorbents, non living plant material, such as potato peels ${ }^{10}$, eggshells ${ }^{11}$, orange, lemon and banana peels ${ }^{12,13}$, coffee husks ${ }^{14}$, rice hull ${ }^{15}$, cotton and maize stalks and rice straw ${ }^{16}$ possess better adsorption capacities for a large spectrum of heavy metals depending on their chemical composition and operating conditions. For example, it was demonstrated that the efficiency removal of cadmium, iron and zinc by rice hull is higher than sawdust, sugarcane bagasse and wheat straw in the order of $98,15 \%, 96,90 \%, 93,00 \%$ and $91,19 \%$ respectively ${ }^{16}$. The high heavy metals sequestration of rice hull than others agriculture waste biosorbents was probably due to the presence of silanol groups in its structure as the authors suggested. In the study achieved by Mosa et al., ${ }^{17}$, it was established that the adsorptive power of heavy metals decreases in the order of cotton stalks, maize stalks and rice straw. They attributed the potent removing efficacy of cotton stalks to its highest content of cellulose, hemicellulose and lignin. Nigella sativa L. (Nigella) is an annual herbaceous plant belonging to the ranunculaceae family growing in Asia, in northern Africa and in southern Europe. The black seeds of Nigella, known in Arabia as 'Al-Habba Al-Sawdaa' black cumin or Habatul-Barakah, have long been used as spice in food and in folk medicine in the worldwide particularly in the Middle and Far East for a wide range of diseases ${ }^{18,19,20}$. The chemical composition of the seeds of Nigella has been largely investigated $^{21,22,23}$. The analysis of whole mature seeds from different geographic and climatic origins showed that the crude protein vary from $20 \%$ to $27 \%$, carbohydrates from $23.5 \%$ to $40,0 \%$ and total lipid from $28,48 \%$ to $40.35 \%$. Polyphenols a secondary metabolite constitute another compound of this seeds with a high content in order of 27,8 mg equivalent acid gallic per gram of extract ${ }^{24}$. In addition, the oily fraction of the seeds is the active ingredients especially the essential oils ${ }^{25,26}$ that possess a potential multi-purposes product largely used in phytotherapy and alternative medicine. For this reasons, oil factory was grown in Algeria, which engender, every year, several hundreds of tons of Nigella seeds meals waste that were discarded in nature as a fertilizer or used only for animal breeding as a complement. The aim of this study, the first at our knowledge, consists to establish the adsorptive properties of the biomass of Nigella seeds meals waste as bioadsobent toward $\mathrm{Pb}$ (II), a divalent metal ion that is predominantly present in the effluents of battery factory and lead refining unit implanted at Sétif (East part region of Algeria). The adsorption approach was conducted in batch by using synthetic aqueous solutions at different contact time by varying the concentration of this metal at various $\mathrm{pH}$ using different biomass sorbent dose. The adsorption isotherms and sorption kinetics models of $\mathrm{Pb}(\mathrm{II})$ ions onto $\mathrm{N}$. sativa seeds waste were also established. Fourier transform infrared spectroscopy (FTIR) was used to elucidate the adsorption process. Finally, the adsorption capacities was carried out by using a given amount of this bulk biomass in removing lead from activated sludge and liquid effluent from factory.

\section{MATERIALS AND METHODS}

\section{Materials}

All the necessary chemicals are of analytical grade and obtained from Sigma-Aldrich (USA). Stock solution (1000 mg/L), which was prepared by dissolving $\mathrm{Pb}\left(\mathrm{NO}_{3}\right)_{2}$ in deionized water. The sample solutions were prepared at the required concentrations by serial dilution of stock solution for practical use. The $\mathrm{pH}$ value of the solution was measured with a digital pH meter (AR 25 Dual Channel Fisher Scientific, Canada) using solid electrode calibrated with a standard buffer solution. The $\mathrm{pH}$ value of the solutions was adjusted by addition of $0.1 \mathrm{M} \mathrm{HCl}$ or $\mathrm{NaOH}$. Atomic absorption 
spectrophotometer (Perkin Elmer PinAA-900F, Canada) was used to assess the $\mathrm{Pb}(\mathrm{II})$ ), before and after biosorption, content in aqueous solution. FT-IR spectrophotometer (Shimadzu, Algeria) in the range of $500-4000 \mathrm{~cm}^{-1}$ was used to identify the functional groups of seed biomass powder, preliminarily dispersed in $\mathrm{KBr}$ pellets, before and after sorption process.

\section{METHODS}

\section{Preparation of biosorbent}

Firstly, the seeds of Nigella obtained from a local market of Tamalous (East part of Skikda, Algeria) during the end of 2015 were pre-treated to remove the surface impurities and then crushed into fine powder by mechanical grinder. The powder was sieved to an average size of $200-500 \mu \mathrm{m}$ in order to allow a good mass transfer between sorbat and biosorbent. The Nigella seeds meals waste biomass was prepared by defatted action, which was achieved by organic solvent instead mechanic system as it done in oil factory. For that, an amount of powder was soaked in hexane in a ratio of $1 / 5$ weight per volume for $2 \mathrm{~h}$ under agitation. This operation was repeated until total lipids were completely removed. Then, the biosorbent was filtered and dried in an incubator at $40{ }^{\circ} \mathrm{C}$ for $24 \mathrm{~h}$ for complete solvent removal. Finally, material was stored in an air tight bottle to protect it from contaminants and humidity until it uses as a biosorbent for the removal of $\mathrm{Pb}$ (II) experiments.

Batch adsorption experiments were carried out in flasks by adding $0.07 \mathrm{~g}$ of $N$. sativa seeds biomass in $10 \mathrm{ml}$ of aqueous $\mathrm{Pb}$ (II) solution at desired initial $\mathrm{pH}(2,4,6,8$ and 10), initial metal ion concentration (93, 764, 1190, 1400 and $1819 \mathrm{mg} / \mathrm{L})$ and contact time (90, 720, 1140 and 2880 minutes). The contents were shaken at 200rpm on at room temperature. After completion of each batch, the solution was separated by filtration with Whatman filter paper 41 followed by centrifugation at 3000rpm for $10 \mathrm{~min}$. and the filtrate was analyzed for the remaining metal concentration in the sample using atomic absorption spectrophotometer. The amount of metal ion sorbed per unit mass of the biosorbent $(\mathrm{mg} / \mathrm{g})$ was evaluated by using the following equation 1 ,
$Q=\frac{\left(C_{0}-C e\right) V}{m}$

The biosorption percentage (BS) of $\mathrm{Pb}$ (II) ions was calculated using the equation 2 ,

BS $\%=\frac{\left(C_{0}-C e\right)}{C_{0}} \times 100$

Where $\mathrm{Q}(\mathrm{mg} / \mathrm{g})$ is the adsorption capacity, $\mathrm{C}_{0}$ and $\mathrm{Ce}$ denote respectively the initial and equilibrium concentrations of metal ion $(\mathrm{mg} / \mathrm{L})$, $\mathrm{V}(\mathrm{L})$ is volume of adsorbate and $\mathrm{m}(\mathrm{g})$ is the amount of adsorbent. All the experiments were performed in duplicate and the results are the average values.

\section{Characterization of biosorbent by FTIR}

FTIR spectroscopy is a well known times saving method to characterize and identify functional groups ${ }^{27}$ (Grube et al., 2008). Therefore, FTIR spectrum was used as a tool to identify the characteristic functional groups that might be responsible for binding of metal ions. The FTIR spectra of before treatment and $\mathrm{Pb}$ (II) loaded $N$. sativa seeds were recorded in the range of $4000-500 \mathrm{~cm}^{-1}$ by pellet $\mathrm{KBr}$ method.

\section{Trial removal of lead on real effluents}

The $N$. sativa seeds biosorbent was tested for the removal of $\mathrm{Pb}$ (II) from wastewater effluents using predetermined optimum biosorption conditions. Material was brought from an activated sludge tank located in wastewater treatment plant in St. Hyacinthe, QC, Canada. The initial concentration of the mix liquor suspended solids was around $4000 \mathrm{mg} / \mathrm{L}$. The tests were conducted on two different samples, i) directly on the activated sludge, and ii) on the decanted effluent of the activated sludge preliminarily centrifuged at $3000 \mathrm{rpm}$ and filtrated through a filter paper Whatman 41 . Since the activated sludge contained traces of some metals only, the samples were adjusted to the level of $\mathrm{Pb}(\mathrm{II})$ to $764 \mathrm{mg} / \mathrm{L}$. The $\mathrm{pH}$ value was not adjusted, and tests were conducted in neutral conditions ( $\mathrm{pH}$ 6.35). An amount of $0.07 \mathrm{~g}$ of $N$. sativa seeds biomass were added to 10 $\mathrm{ml}$ of both samples and were exposed to $360 \mathrm{~min}$. of contact time at ambient temperature. After treatment, the lead content in supernatants of both samples was determined by atomic absorption spectrophotometry 


\section{RESULTS AND DISCUSSION}

\section{Effect of the initial metal ions concentration}

The sorption capacity $(\mathrm{Q} \mathrm{mg} / \mathrm{g})$ of lead onto $N$. sativa seeds biomass increases from 7.79 to 39 , $7 \mathrm{mg} / \mathrm{g}$, when the initial $\mathrm{Pb}(\mathrm{II})$ ions concentration in medium increases from 93 to $1819 \mathrm{mg} / \mathrm{L}$ respectively (Fig. 1 A). This common finding and phenomenon could be probably due to a full contact or collision between sorbat and sorbent as established by Wang and Chen ${ }^{9}$. Inversely, the removal efficacy decreases by increasing the initial metal ion concentration. In fact, an increase of $\mathrm{Pb}(\mathrm{II})$ concentration in the same range result in a decrease of the removal efficiency from 99, 4 to $42,13 \%$. At low concentration, most of the metal ions in solution interact with active sites on the biosorbent resulting in high percentage removal until the saturation plateau was attained ${ }^{28,29}$. However, at higher concentrations the diffusion of metal ions into biomass surface was achieved via interparticle interactions. The difference between bulk and surface metal ions concentration is one of the driving forces to overcome the resistance to adsorption in the absence of the mass transfer resistance surface and bulk concentrations ${ }^{28}$. This is due to high initial $\mathrm{Pb}$ (II) ion concentration, where the number of moles of metal ions available to the surface area might be high, therefore functional adsorption becomes dependent on the initial metal ion concentration ${ }^{28}$. This result is comparable with to those reported in bibliography for other adsorbents ${ }^{30}, 31$. Consequently, the initial concentration of lead of $764 \mathrm{mg} / \mathrm{L}$ was used in subsequent tests in this study.

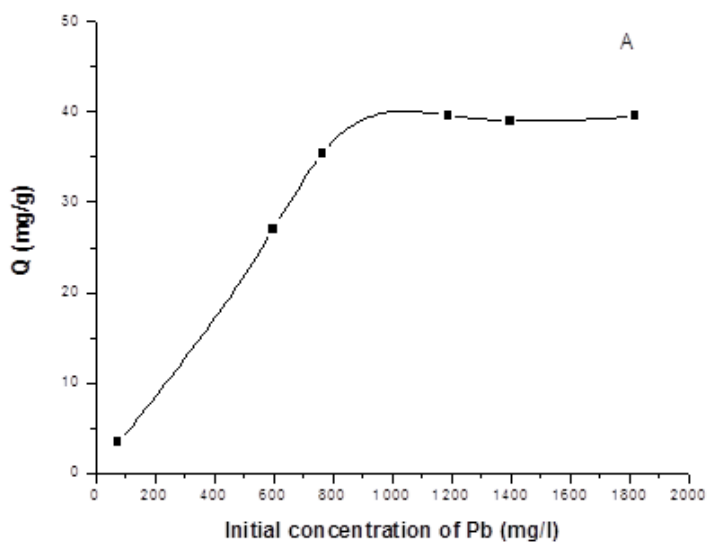

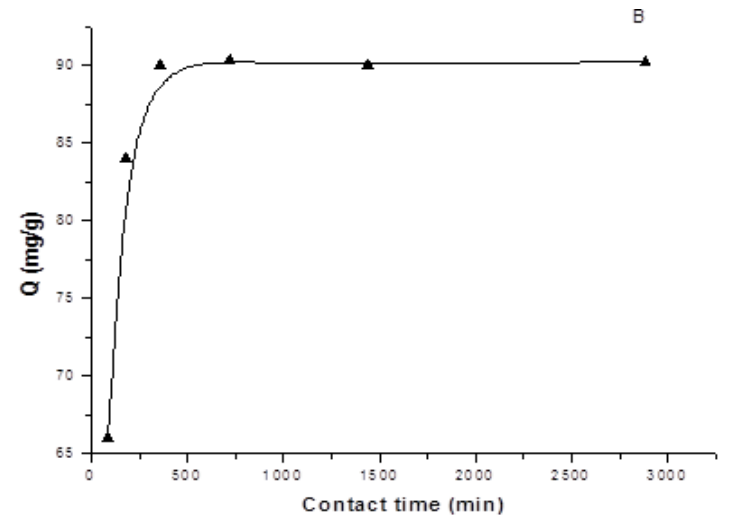

Fig. 1. Biosorption capacity of $\mathrm{Pb}$ (II) onto nigella biomass.at varying initial concentration $(A)$ and contact time (B)

\section{Effect of contact time}

The equilibrium time is one of the most important parameters for an economical wastewater treatment system. Fig. 1B shows the effect of contact time for the biosorption of $\mathrm{Pb}(\mathrm{II})$ by the $N$. sativa seeds biomass. The capacity of biosorption for $\mathrm{Pb}(\mathrm{II})$ was rapid in the initial stage (90-180 minutes). This is probably due to the biosorption of metal ions onto the $N$. sativa seeds exterior surface. In the subsequent stages, the biosorption became slow when the ions diffused into the interior surface. Furthermore, this can also be attributed to more vacant surface binding sites available for biosorption during the initial stage ${ }^{32}$. A maximum percentage metal removal of $80 \%$ and the capacity of biosorption of $90.31 \mathrm{mg} / \mathrm{g}$ was observed at 360 min. for $\mathrm{Pb}(\mathrm{II})$. Conversely, after a certain time, the capacity of biosorption for ion metal decreased when approaching $720 \mathrm{~min}$. when biosorption sites became saturated and repulsive forces between the solute molecules on the solids came into play ${ }^{33,34}$. Similar results have also been reported previously for $\mathrm{Pb}(\mathrm{II})$ ions absorption into pomegranate peel $\mathrm{l}^{35}$ and tea waste ${ }^{36}$. The contact time of 360 min. was used in subsequent tests of this study.

\section{Effect of initial pH}

The $\mathrm{pH}$ of medium in biosorption phenomenon is one of the pivotal parameters that affect the ionization of the surface functional groups and specification of metal ions and thus affecting the interactions of the metal ions at interface. In order to evaluate the adsorption of $\mathrm{Pb}$ (II) ions onto the $N$. sativa seeds biomass, the experiments were conducted at $\mathrm{pH}=2,4,6,8$ and 10 , while the biosorbent dose- contact time and initial metal 
concentration were $0.07 \mathrm{~g}, 360 \mathrm{~min}$. and $764 \mathrm{mg} / \mathrm{L}$, respectively. The $\mathrm{pH}$ dependence of equilibrium adsorption data of $\mathrm{Pb}$ (II) ion is shown in Fig. $2 \mathrm{~A}$. The $\mathrm{pH}$ profile shows that the removal of $\mathrm{Pb}$ (II) ion increase with solution $\mathrm{pH}$ and reaches the maximum value of $53.34 \%$ for $\mathrm{Pb}$ (II) at $\mathrm{pH}$ of 4 . The sorption capacity $(\mathrm{Q} \mathrm{mg} / \mathrm{g})$ increased until $23 \mathrm{mg} / \mathrm{g}$. At low $\mathrm{pH}$ values, more protons compete with the metal cations for the biosorption sites as the biosorbent surface would be closely associated with hydronium ions ${ }^{37}$. As $\mathrm{pH}$ increases, concentration of the hydronium ions decrease and the functional groups on the biosorbent surface become negatively charged, making the biosorbent surface more readily available for metal cations biosorption ${ }^{38,39}$, thus increasing the biosorption capacity of the biosorbent. The fluctuations in biosorption yield were not only related to the formation of soluble hydroxylated complexes of the metal ions (lead ions in the form of $\mathrm{Pb}(\mathrm{OH})_{2}$ ) but also to the ionized nature of the cell wall surface of the $N$. sativa seeds biomass under the studied $\mathrm{pH}$. It can be speculated that isoelectric point of the biosorbent is approximately around a $\mathrm{pH}$ of 4 . It was concluded that the biosorbent was active in a large spectra of $\mathrm{pH}$, ranged from 4.0 to 7.0 . In this study the $\mathrm{pH}$ of 4.5 was applied.

\section{Effect of the biosorbent dose}

In adsorption between sorbat and sorbent in a given medium, the dosage of biomass is an important parameter, which determines the capacity of uptake in function of initial concentration. The biosorption of $\mathrm{Pb}$ (II) onto $\mathrm{N}$. sativa seeds as a function of the biosorbent dose was studied by varying the amount of biosorbent from 0.01 to $0.2 \mathrm{~g} / 10 \mathrm{ml}$ solution at $\mathrm{pH} 4.5$ and $764 \mathrm{mg} / \mathrm{L} \mathrm{Pb}$ (II) initial concentration for $360 \mathrm{~min}$. contact time.

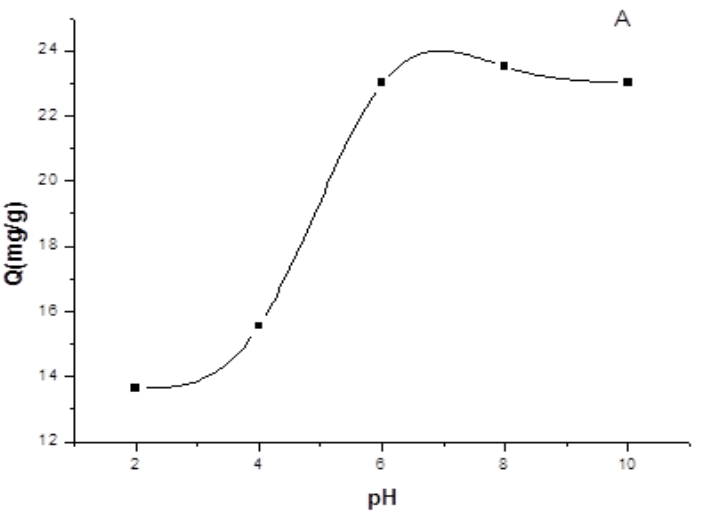

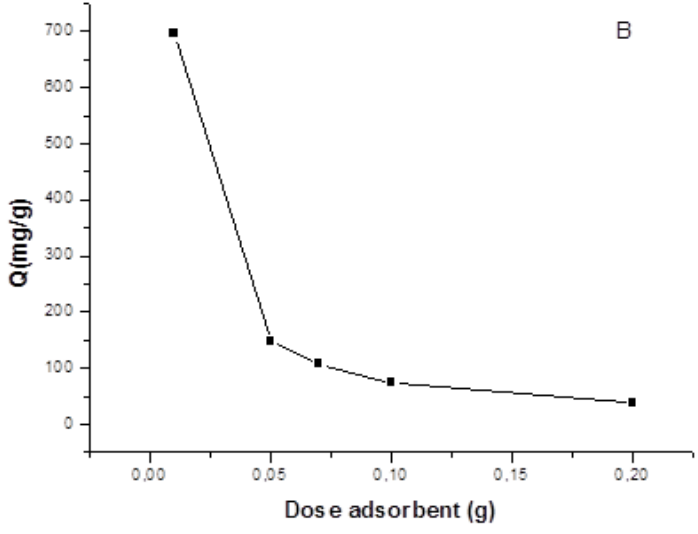

Fig. 2. Biosorption capacity of $\mathrm{Pb}$ (II) onto nigella biomass at various initial $\mathrm{pH}(\mathrm{A})$ and sorbent dosage (B)

The effect of the sorbent dose on the $Q$ value $(\mathrm{mg} / \mathrm{g})$ is shown in Fig. 2B. At $0.01 \mathrm{~g}$ biosorbent dose for $10 \mathrm{ml}$ of solution, the biosorption capacity of the $N$. sativa seeds biomass is high and tends to decrease at higher doses of biomass. This result demonstrates clearly that a very small dose of biomass was required to remove the provided amount of lead. In fact, this behavior may be due to the availability and accessibility of more adsorption sites at low dosage. At high biomass dosage the sites became less available due to the steric overlapping. In literature, similar results in agreement of ours were obtained on different biomass for the adsorption of $\mathrm{Pb}$ (II) in function of dosage $^{40,41}$, Subsequently, the dose of $0.07 \mathrm{~g}$ was applied in the tests of this study.

\section{Biosorption isotherms}

To examine the relationship between adsorbed $(Q e)$ and equilibrium concentrations $(C e)$ of lead onto Nigella seeds biomass, sorption isotherm models of Langmuir and Freundlich ${ }^{42}$, which describe the equilibrium relationships between sorbent and sorbate in solution are applie. Sorption equilibrium is established when the concentration of sorbate in the bulk solution is in dynamic balance with that of the interface. To get the equilibrium data, the initial concentration of $\mathrm{Pb}$ (II) varied, while the biosorbent dose of biomass was kept constant. In Langmuir isotherm, the biosorption takes place at specific homogeneous sites of sorbent and was successfully applied in many process of monolayer biosorption. The linear form of the Langmuir isotherm is shown in equation 3. 


$$
\frac{C_{e}}{Q_{e}}=\frac{1}{K L Q_{\max }}+\frac{C_{e}}{Q_{\max }}
$$

Where $Q_{e}$ is the metal ion sorbed $(\mathrm{mg} / \mathrm{g})$, $\mathrm{Ce}$ the equilibrium concentration of metal ion solution, and $\mathrm{K}_{\mathrm{L}}$ is the Langmuir adsorption constant. A plot of $C_{e} / Q_{e}$ versus $C_{e}$ for the biosorption of $\mathrm{Pb}(\mathrm{II})$ onto the $N$. sativa seeds biomass gives a straight line (Fig. 3A). On the opposite, in Freundlich isotherm a heterogeneous empirical systems, which describe the phenomenon of adsorption at interface was employed. The log form of equation 4 was obtained by plotting $\log Q_{e}$ versus log Ce (Figure 3B).

$$
\log Q_{e}=\frac{1}{n}\left(\log C_{e}\right)+\log K_{f}
$$

Where $\mathrm{Ce}(\mathrm{mg} / \mathrm{L})$ is the equilibrium concentration, $Q_{e}(\mathrm{mg} / \mathrm{g})$ is the amount of metal ions adsorbed per specified amount of adsorbent at equilibrium; $K_{f}$ and $1 / n$ are the constants. The adsorption parameters evaluated from their isotherms (Fig. $3 \mathrm{~A}$ and $\mathrm{B}$ in shadow frame) demonstrate clearly that theoretical calculated adsorption capacity $\left(Q_{\max }\right)$ of $\mathrm{Pb}(\mathrm{II})$ at interface found in Langmuir model was in agreement with the experimentally determined sorption $(39,7 \mathrm{mg} / \mathrm{g})$. On the other hand, the correlation coefficient in Langmuir isotherm model is higher than the exhibited one by Freundlich. Thus, these two parameters suggest that the Langmuir isotherm describe better the sorption phenomenon than the Freundlich model.

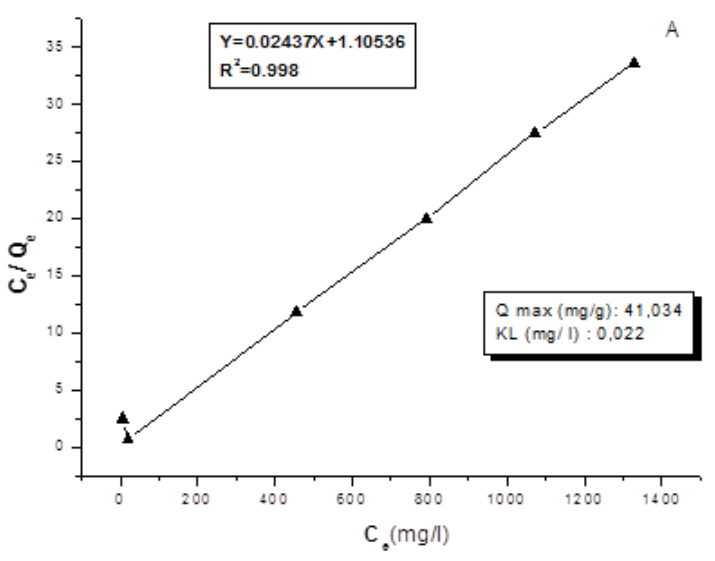

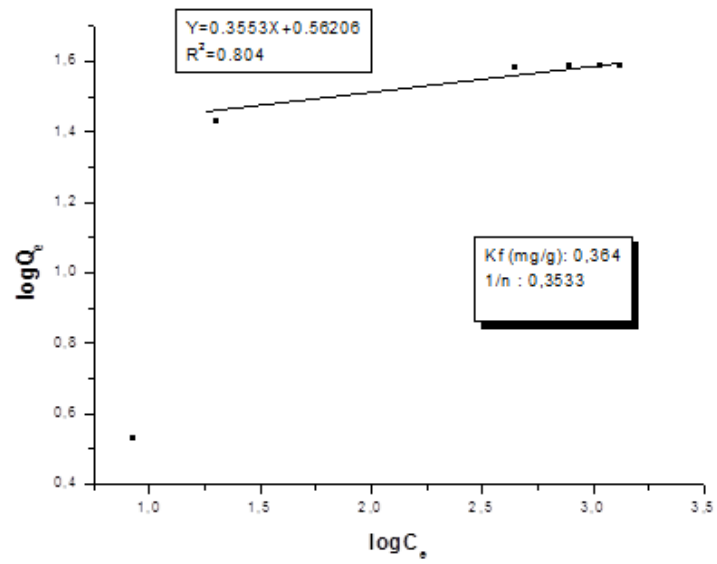

Fig. 3. Langmuir (A) and Freunlich (B) biosorption isotherms of $\mathrm{Pb}$ (II) onto nigella seeds biomass

\section{Biosorption Kinetics}

The rate controlling mass transfer, chemical reaction processes and biosorption mechanism can be effectively investigated by different kinetic models. In the present study, the pseudo-first-order and pseudo-second order models were used to determine the mechanism of the biosorption process. In the model of the pseudo-first-order given by the equation 5 was used in this study ${ }^{42}$.

$$
\log \left(Q_{e}-Q_{t}\right)=\log Q_{e}-\frac{t K}{2303}
$$

Where $Q_{t}$ is the amount of metal ions adsorbed $(\mathrm{mg} / \mathrm{g})$ at any arbitrary time $t(\mathrm{~min}),. \mathrm{Q}_{\mathrm{e}}$ is the amount of metal ion adsorbed $(\mathrm{mg} / \mathrm{g})$ at equilibrium and $\mathrm{K}_{1}$ is the pseudo-first order reaction rate constant for adsorption $\left(\mathrm{min}^{-1}\right)$ and $t$ is the time (minutes). The plots of log (Qe-Qt) versus log Qe of the pseudo-first-order model for $\mathrm{Pb}$ (II) biosorption on the $N$. sativa seeds biomass is shown in Fig. $4 \mathrm{~A}$. For the pseudo-second-order model assumes that the rate of occupation of biosorption sites is proportional to the square of the number of unoccupied sites ${ }^{42}$. The linear form can be expressed from equation 6 .

$\frac{\mathrm{t}}{\mathrm{Q}_{\mathrm{t}}}=\frac{1}{\mathrm{Q}_{\mathrm{e}} \mathrm{K}_{2}}+\frac{\mathrm{t}}{\mathrm{Q}_{\mathrm{e}}}$

Where $Q_{e}$ is the amount of metal ion adsorbed $(\mathrm{mg} / \mathrm{g})$ at equilibrium and $\mathrm{K}_{2}$ is the rate constant of pseudo-second-order model $\left(\mathrm{g} \mathrm{mg}^{-1} \mathrm{~min}^{-1}\right)$. The plots of $\left(t / \mathrm{Q}_{\mathrm{t}}\right)$ versus $\mathrm{t}(\mathrm{min}$.) of the pseudo-second-order model for $\mathrm{Pb}(\mathrm{II})$ 
biosorption on the $N$. sativa seeds biomass is shown in Figure $4 \mathrm{~B}$.

In view of the obtained of the kinetic parameters (in shadow frame), it appears that the uptake capacity in the pseudo-second order reflect well the nature of kinetic due to the similarity with the experimental value comparing to the pseudo-first order where the uptake represent only $56 \%$. In effect, the correlation coefficient $\left(R^{2}\right)$ value of the pseudo-second-order kinetic model is very close to one compared to the pseudo-first order that it could not used to describe the entire biosorption process. Consequently, it can be concluded that the biosorption process for $\mathrm{Pb}(\mathrm{II})$ ions at biomass interface followed a pseudo-second-order reaction.

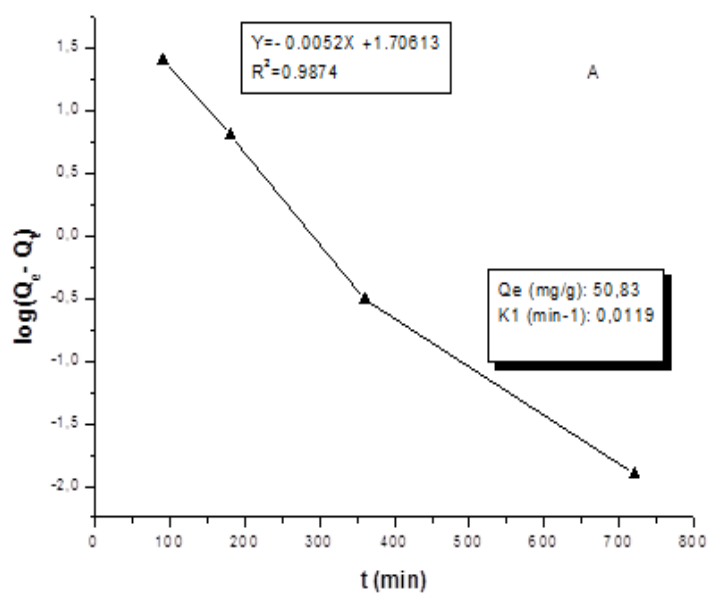

\section{Characterization of Biosorbent by FTIR}

The FTIR spectra of before treatment and $\mathrm{Pb}$ (II) loaded $N$. sativa seeds are shown in Fig. 5 . The native biomass of $N$. sativa seeds before sorption lead (Fig. $5 \mathrm{~A}$ ) showed a broad band at $3404.36 \mathrm{~cm}^{-1}$ indicating the presence of $-\mathrm{OH}$ group. The peak at $3008.95 \mathrm{~cm}^{-1}$ shows $\mathrm{N}-\mathrm{H}$ stretching of amino acids as well as alkenes. The peak at $1745.58 \mathrm{~cm}^{-1}$ depicts carbonyl $\mathrm{C}=\mathrm{O}$ group. The peak at $1711.03 \mathrm{~cm}^{-1}$ shows aldehyde. The peak at $1654.92 \mathrm{~cm}^{-1}$ shows stretching vibration of $\mathrm{C}-\mathrm{OH}$ band from proteins and alkenes.

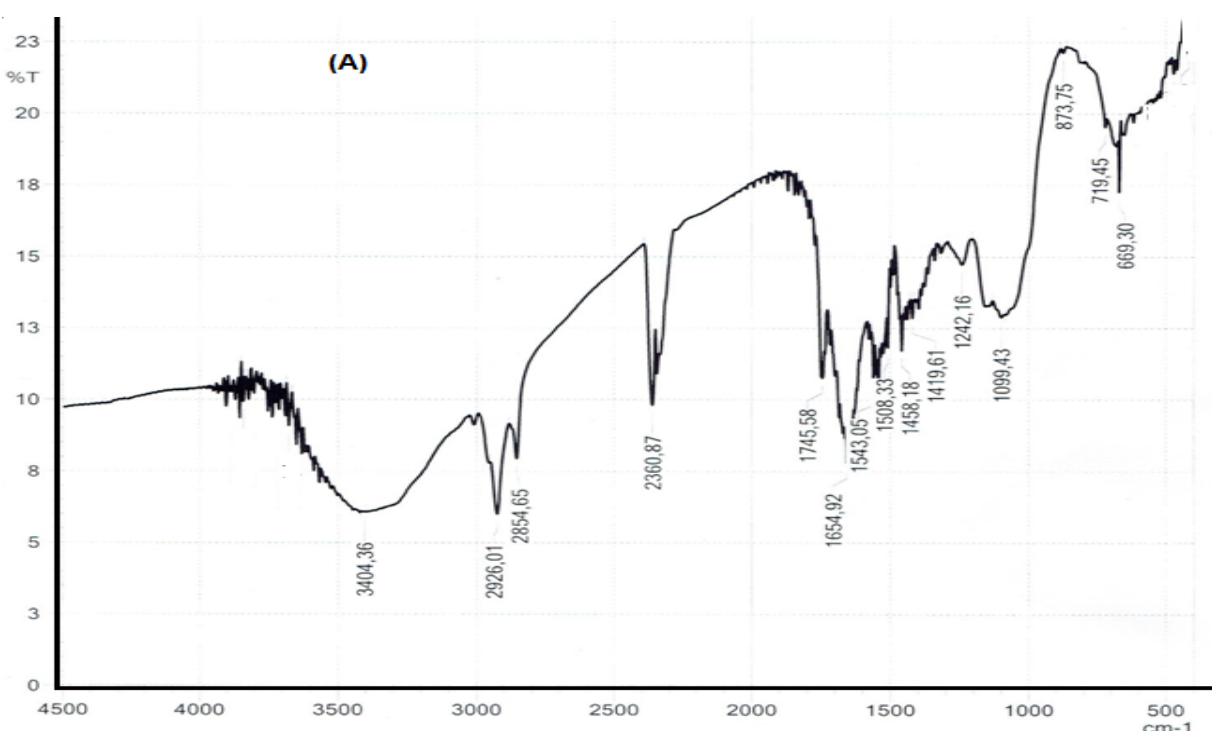

Fig. 5(A) 


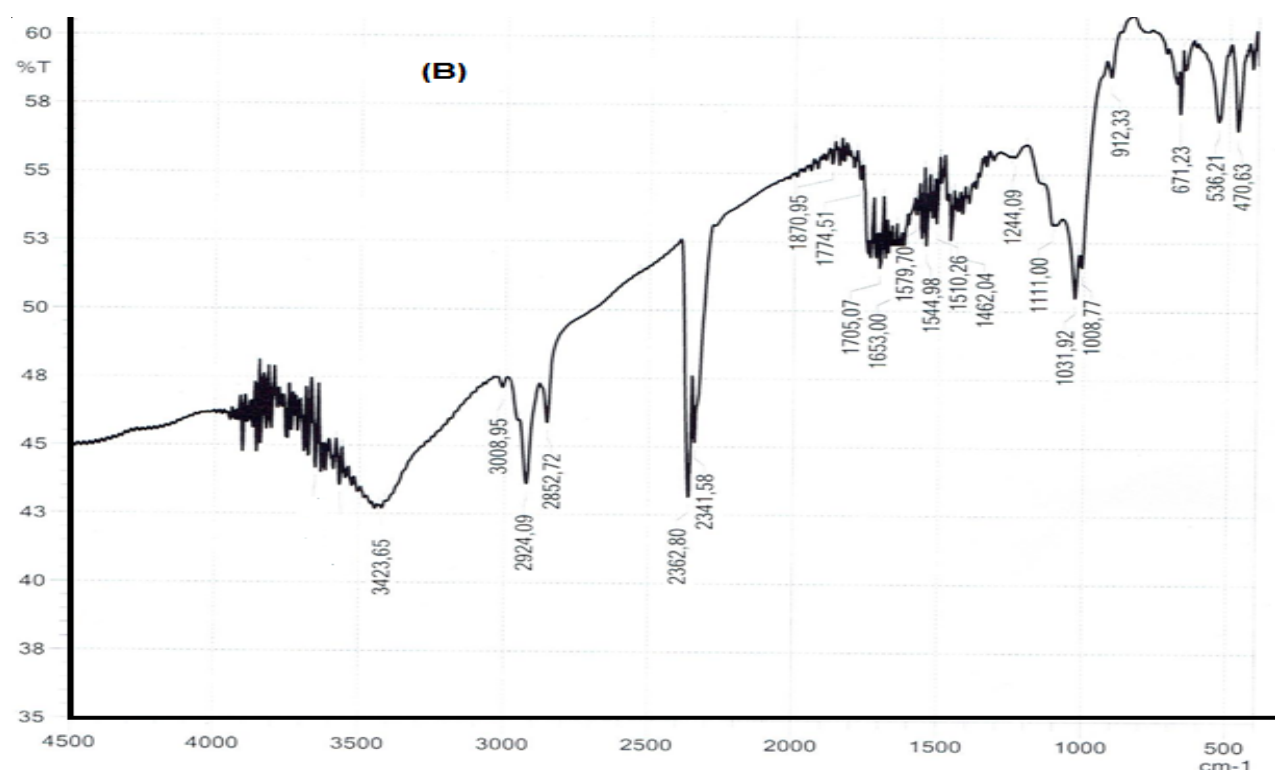

Fig. 5. FTIR spectra of $\mathrm{N}$. sativa seeds biomass before (A) and after $\mathrm{Pb}$ (II) adsorption (B)

\section{Efficiency removal of lead on real effluents}

The obtained results of removing lead on the two studied effluents demonstrated a high efficiency sequestration of $\mathrm{Pb}(\mathrm{II})$. In fact, $97 \%$ of lead was removed in the sludge sample and $64 \%$ in decanted/filtrated effluent. Such results confirmed once more the efficient removal of $\mathrm{Pb}$ (II) heavy metal ion by $N$. sativa seeds biosorbent in aqueous systems. It can be concluded that $N$. sativa seeds biomass have a great potential for sustainable treatment of water and wastewater with respect to heavy metals.

\section{CONCLUSION}

Nigella sativa seeds biomass possesses an important sorption capacity towards $\mathrm{Pb}$ (II) under optimum conditions particularly $\mathrm{pH}$ medium, time contact and sorbent dose, which play a pivotal role in this phenomenon. The FTIR analysis indicates the implication of hydroxyl and carbonyl groups in the interactions at interface. Langmuir isotherm model with an adsorption capacity of $41.034 \mathrm{mg} / \mathrm{g}$ and pseudo-second order kinetic with an $\mathrm{r}^{2}$ close to 1 fitted well the experimental sorption data. The removal of $\mathrm{Pb}$ (II) from sludge that can attain $97 \%$ confirms the previous findings. So, this biomass is an effective sorbent for sorption of $\mathrm{Pb}$ (II).

\section{ACKNOWLEDGEMENT}

The authors express their gratitude to Natural Sciences and Engineering Research Council of Canada (NSERC) as well as to Mrs Klara Pokrzywko for their helpful assistance and the University of Skikda for its financial doctoral study fellowship.

This research did not receive any specific grant from funding agencies in the public, commercial, or not-for-profit sectors.

\section{REFERENCES}

1. Garnier, R.. Toxicity of lead and lead compounds. EMS-Toxicologie Pathologie., 2005, 2, 67-88.

2. Fu, F.; Wang, Q. Removal of heavy metal ions from wastewaters: A review. J. Environ. Manage., 2011, 92, 407-418.
3. Bhattacharyya, K.G.; Gupta, S.S. Adsorption of few heavy metals on natural and modified kaolinite and montmorillonite-Review. Adv. Colloid Interface Sci., 2008, 140, 114-131.

4. Patterson, J.W. Waste water Treatment Technology. Ann Arbor Science Pub. Inc., 
Ann Arbor, MI, USA., 1985, 199-215.

5. Pulkka, S.; Martikainen, M.; Bhatnagar, A.; Sillanp, M. Electrochemical methods for the removal of anionic contaminants from water-A review. Sep. Pur. Technol., 2014,132, 252-271.

6. Abdel-Raouf N.; Al-Homaidan, A.A.; Ibraheem, I.B. Microalgae and wastewater treatment. Saudi J. Bio. Sci., 2012, 19, 257-275.

7. Bilal, M.; Shah, J.A.; Ashfaq, T.; Hussain, S.M.; Tahir, A.A.; Pervez, A., Haroun, H.; Mahmood. Q.. Waste biomass adsorbents for copper removal from industrial wastewater-A review. J. Hazard. Mater., 2013, 263, 322-333.

8. Siddiquee, S.; Rovina, K.; Al Azad, S.; Naher, L.; Suryani, S.; Chaikaew, P.. Heavy Metal Contaminants Removal from Wastewater Using the Potential Filamentous Fungi Biomass: A Review. J. Microbio. Biochem. Technol., 2015, 7(6), 384-393.

9. Wang, J.; Chen, C. Biosorbents for heavy metals removal and their future. Biotech. Adv., 2009, 27,195-226.

10. Nguyen, T.A.H.; Ngo, N.H.; Guo, W.S.; Zhang, J.; Liang, S.; Yue Q.Y.; Li, Q.; Nguyen, T.V. Applicability of agriculture waste and byproducts for adsorptive removal of heavy metals from wastwewater. Bioresour. Technol., 2013,148, 574-585.

11. Aman, T.; Kazi, A.A.; Sabri, M.U.; Bano, Q.. Potato peels as solid waste for the removal of heavy metal copper (II) from waste water/ industrial effluent. Colloids Surf. B., 2008, 63,116-121.

12. Jai, P.H.; Zook, J.S.; Kyu, Y.J.; Gil, K.B., Mok, L.S. Removal of heavy metals using waste eggshell. J. Environ. Sci., 2007, 19, 1436-1441.

13. Schiewer, S.; Patil, S.B. Modelling the effect of $\mathrm{pH}$ on biosorption of heavy metals by citrus peels. J. Hazard. Mater., 2008, 157, 8-17.

14. Kelly-Vargas, K.; Cerro-Lopez, M.; ReynaTellez, S.; Bandala, E.R.; Sanchez-Salas, J.L. Biosorption of heavy metals in polluted water, using different waste fruit cortex. Phys. Chem. Earth., 2012, 39, 26-39.

15. Oliviera, L.; Franca, A.S.; Alves, T.M.; Rocha, S.D.F.. Evaluation of untreated coffee husks as potential biosorbents for treatment of dye contaminated waters. J. Hazard. Mater., 2008, $155,507-512$.
16. Osman, H.E.; Badwy, R.K.; Ahmad, H.F. Usage of some agricultural by products in the removal of some heavy metals from industrial wastewater. J. Phytol., 2010, 2, 51-62.

17. Mosa, A.A.; El-Ghamry, A.; Trüby, P. Chemically modified crop residues as a lowcost technique for the removal of heavy metal ions from wastewater. Water Air Soil Pollut., 2011, 217, 637-647.

18. Goreja, WG.. Black Seed: Nature's Miracle Remedy. Amazing Herbs Press; NewYork, NY7, USA. 2003.

19. Ghedira, K. La nigelle cultivée: Nigella sativa L.( Ranuunculaceae), Phytothérapie., 2006, 5, 220-226.

20. Hussain, D.A.S.; Hussain, M.M. Nigella sativa (black seed) is an effective herbal remedy for every disease except death - a Prophetic statement which modern scientists confirm unanimously: A review. Advancement in Medicinal Plant Research., 2016, 4(2), 27-57.

21. Ramadan, MF.; Mörsel, TJ. Neutral lipid classes of black cumin (Nigella sativa L.) seed oils. Eur. Food Res. Technol., 2002, 214, 202-206.

22. Atta, MB. Some characteristics of nigella (Nigella sativa $\mathrm{L}$ ) seed cultivated in Egypt and its lipid profile. Food Chem., 2003, 83, 63-68.

23. Cheikh-Rouhou, S.; Besbes, S.; Hentati, B.; Blecker, C.; Deroanne, C.; Attia, H. Nigella sativa L: Chemical composition and physicochemical characteristics of lipid fraction. Food Chem., 2007, 101, 673-681.

24. Mariod, A.A.; Ibrahim, R. M.; Ismail, M.; Ismail, N.. Antioxidant activity and phenolic content of phenolic rich fractions obtained from black cumin (Nigella sativa) seed cake. Food Chem., 2009, 116, 306-312.

25. Benkaci-Ali, F.; Baaliouamer, A.; Meklati BY. Kinetic Study of Microwave Extraction of Essential Oil of Nigella sativa L. Seeds. Chromatographia., 2006, 64, 227-231

26. Wajs, A.; Bonikowski, R.; Kalemba, D.. Composition of essential oil from seeds of Nigella sativa L. cultivated in Poland. Flavour Flagr. J., 2008, 23, 126-132.

27. Grube, M.; Muter, O.; Strikauska, S.; Gavare, M.; Limane, B. Application of FTIR spectroscopy for control of the medium composition during the biodegradation of 
nitro aromatic compounds. J. Ind. Microbiol. Biotechnol., 2008, 35, 1545-1549.

28. Dubey, A.; Shiwani, S. Adsorption of lead using a new green material obtained from Portulaca plant. Int. J. Environ Sci. Technol., 2012, 9, 15-20.

29. Moyo, M.; Guyo, U.; Mawenyiyo, G.; Zinyama, N. P.; Benias, C. Nyamunda arula seed husk (Sclerocarya birrea) biomass as a low cost biosorbent for removal of $\mathrm{Pb}(\mathrm{II})$ and $\mathrm{Cu}(\mathrm{II})$ from aqueous solution. J. Ind. Eng. Chem., 2015, 27, 126-132.

30. Sheku, A.K.; Mambo, M., Caliphs, M.Z.; Jonathan, O.O. Biosorption of $\mathrm{Pb}$ (II) from aqueous solution using Rooibos shoot powder (RSP). Desalinisation Water Treat., 2015, 1-9.

31. Upenyu, G.; Joylene, M.; Mambo, M. . Pb (II) adsorption from aqueous solutions by raw and treated biomass of maize stover-a comparative study. Process Saf. Environ. Prot., 2015, 93,192-200.

32. Freitas, O.M.; Martins, R.J.; Delerue-Matos C.M.; Boaventura, RA.. Removal of Cd(II), Zn(II) and $\mathrm{Pb}$ (II) from aqueous solutions by brown marine macro algae: kinetic modelling. J. Hazard. Mater., 2008, 153, 493-501.

33. Ahlam, M.; Farhan, N.M.; Ahmad, S.; Awwad L.A.A.M.. Kinetic, Equilibrium and Thermodynamic Studies of the Biosorption of Heay Metals by Ceratonia siliqua Bark. Am. J. Chem., 2012, 2(6), 335-342

34. Shiow-Tien, S.; Norasikin, S.; Khairiraihanna, J., Hanapi M. Removal of $\mathrm{Hg}$ (II) from aqueous solution by adsorption using raw and chemically modified rice straw as novel adsorbents. Ind. Eng. Chem. Res., 2013, 52(36), 13092-13101.

35. Kavitha, D.; Namasivayam, C. Experimental and kinetic studies on methylene blue adsorption by coir pith carbon. Bioresour. Technol., 2007, 98, 14-21.

36. El-Ashtoukhy, E.S.Z.; Amin, N.; Abdelwahab, O.. Removal of lead (II) and copper (II) from aqueous solution using pomegranate peel as a new adsorbent. Desalination., 2008, 223, 162-173.

37. Dada, A.O.; Ojediran, J.O.; Olalekan, A.P. Sorption of from Aqueous Solution unto Modified Rice Husk: Isotherms Studies. Adv. Phys. Chem., 2013, 1-6.

38. Liping, D.; Su, Y.; Su, H.; Wang, X.; Zhu, X. Biosorption of copper (II) and lead (II) from aqueous solutions by nonliving green algae Cladophora fascicularis: Equilibrium, kinetics and environmental effects. Adsorption., 2006, 12, 267.

39. Yao, Z.Y.; Qi, J.H.; Wang, L.H.. Equilibrium, kinetic and thermodynamic studies on the biosorption of $\mathrm{Cu}(\mathrm{II})$ onto chestnut shell. J. Hazard. Mater., 2010,174, 137.

40. Bhatti, H.N.; Bajwa, I.I.; Hanif, M.A.; Bukhari, I.H.. Removal of lead and cobalt using lignocellulosic fiber derived from Citrus reticulata waste biomass. Korean J. Chem. Eng., 2010, 27, 218.

41. Alam, M.; Nadeem, R.; Jilani, M.I. Pb (II) removal from wastewater using Pomegranate waste biomass. Int. J. Chem. Biochem. Sci., 2012, 1, 48.

42. Azizian, S.,. Kinetic models of sorption: theoretical analysis. J. Colloid Interface Sci., 2004, 276, 47-52. 